\title{
Re: Selective Non-operative Management of Patients with Abdominal Trauma—is CECT Scan Mandatory?
}

\author{
Varun Arunagiri ${ }^{1}$ (D)
}

Received: 6 May 2016 / Accepted: 19 July 2016 / Published online: 27 July 2016

(C) Association of Surgeons of India 2016

\section{Dear Sir,}

I was glad reading the article "Selective Non-operative Management of Patients with Abdominal Trauma-Is CECT Scan Mandatory?" which was published online on May 2016 [1]. There were few changes the investigator must have done in his study. In the materials and methods section, the investigator had done DPL by open technique using infra-umbilical midline incision which has high false positive rate. The current technique of DPL is either by aspiration or by instilling ringer lactate and then aspiration. More over there were bewildering statements like "FAST was done by the surgeon trained for this purpose"; "This detailed abdominal USG was done by the same radiologist'. According to the author, was the FAST performed by radiologist or the surgeon trained in FAST?

The author had chosen the inclusion criteria as FAST positive and hemodynamically stable or responders. There are clear guidelines suggested in the American Association for the Surgeon of Trauma (AAST) official website for managing stable Blunt Abdominal Trauma and Penetrating Abdominal Trauma, proposed by Eastern Association for the Surgeons of Trauma (EAST). CT Abdomen is the diagnostic modality of choice in all non-operative managements of blunt abdominal injuries including solid visceral injuries (Level-I Evidence) [2]. CT Abdomen is also mandatory in the penetrating abdominal trauma in all stable patients who undergo selective nonoperative management [3].

Varun Arunagiri

surgeonvarun@yahoo.com

1 Institute of General Surgery, Madras Medical College, Chennai, TN, India
"Till date, combined efficacy of physical examination, USG and DPL while using CECT selectively has not been studied" was a controversial statement as many studies regarding this were enumerated in the same guidelines [2].

\section{Compliance with Ethical Standards}

Conflict of Interest The authors declare that they have no competing interests.

Sources of Support None.

\section{References}

1. Kumar S et al. (2016) Selective non-operative management of patients with abdominal trauma - is CECT scan mandatory? Indian J Surg. doi:10.1007/s12262-016-1494-x

2. Hoff WS, Holevar M, Nagy KK, et al. (2002) Practice management guidelines for the evaluation of blunt abdominal trauma: the east practice management guidelines work group. J Trauma 53:602-615

3. Como JJ, Bokhari F, Chiu WC (2010) Practice management guidelines for selective nonoperative management of penetrating abdominal trauma. J Trauma 68:721-733 